\title{
International Survey
}

Stereotactic

and Functional

Neurosurgery
Stereotact Funct Neurosurg 2014;92:71-79

DOI: 10.1159/000355215
Received: March 19, 2013

Accepted after revision: August 22, 2013

Published online: January 30, 2014

\section{Health Economics and Surgical Treatment for Parkinson's Disease in a World Perspective: Results from an International Survey}

\author{
Vincent A. Jourdain ${ }^{\text {a }}$ Gastón Schechtmann ${ }^{b}$ \\ ${ }^{a}$ Neuroscience Research Center, CHUQ and Faculty of Pharmacy, Laval University, Quebec, Que., Canada; \\ ${ }^{b}$ Department of Neurosurgery and Clinical Neuroscience, Karolinska Institutet and University Hospital, \\ Stockholm, Sweden
}

\section{Key Words}

Stereotactic surgery · Parkinson's disease · Deep brain stimulation · Lesions $\cdot$ Health economics

\begin{abstract}
Background: Most studies in the field of neurosurgical treatment for movement disorders have been published by a small number of leading centers in developed countries. This study aimed to investigate the clinical practice of stereotactic neurosurgery for Parkinson's disease (PD) worldwide. Methods: Neurosurgeons were contacted via e-mail to participate in a worldwide survey. The results obtained are presented in order of the countries' economic development according to the World Bank, as well as by the source of financial support. Results: A total of 353 neurosurgeons from 51 countries who had operated on 13,200 patients in 2009 were surveyed. Surgical procedures performed in high-income countries were more commonly financed by a public health care system. In contrast, in lower-middle-income and uppermiddle-income countries, patients frequently financed surgeries themselves, and ablative surgeries were most commonly performed. Unexpectedly, ablative surgery is still used by about $65 \%$ of neurosurgeons, regardless of their country's economic status. Conclusions: This study provides a previously unavailable picture of the surgical aspects of PD
\end{abstract}

across the globe in relation to health economics and sociodemographic factors. Global educational and training programs are warranted to raise awareness of economically viable surgical options for PD that could be adopted by public health care systems in lower-income countries.

(c) 2014 S. Karger AG, Basel

\section{Introduction}

During the last 25 years, there has been a worldwide rebirth in the neurosurgical treatment for movement disorders. Advanced parkinsonian patients may benefit greatly from ablative or deep brain stimulation (DBS) procedures, improving their motor symptoms and quality of life [1]. Today, subthalamic nucleus (STN) and, to a lesser extent, internal globus pallidus (GPi) stimulation are considered the standard procedures for Parkinson's disease (PD) [2]. However, a large majority of the studies

V.A.J. and G.S. contributed equally to this study. Part of this work was presented in abstract form as proceedings of the World Society for Stereotactic and Functional Neurosurgery Interim Meeting, Cape Town, South Africa, November 20-23, 2011 and of the XXth Congress of the European Society for Stereotactic and Functional Neurosurgery, Lisbon, Portugal, September 26-29, 2012.

\section{KARGER}

E-Mail karger@karger.com

www.karger.com/sfn (c) 2014 S. Karger AG, Base

1011-6125/14/0922-0071\$39.50/0
Dr. Gastón Schechtmann

Department of Neurosurgery

Karolinska Institutet and University Hospital

SE-171 76 Stockholm (Sweden)

E-Mail gaston.schechtmann@ karolinska.se 


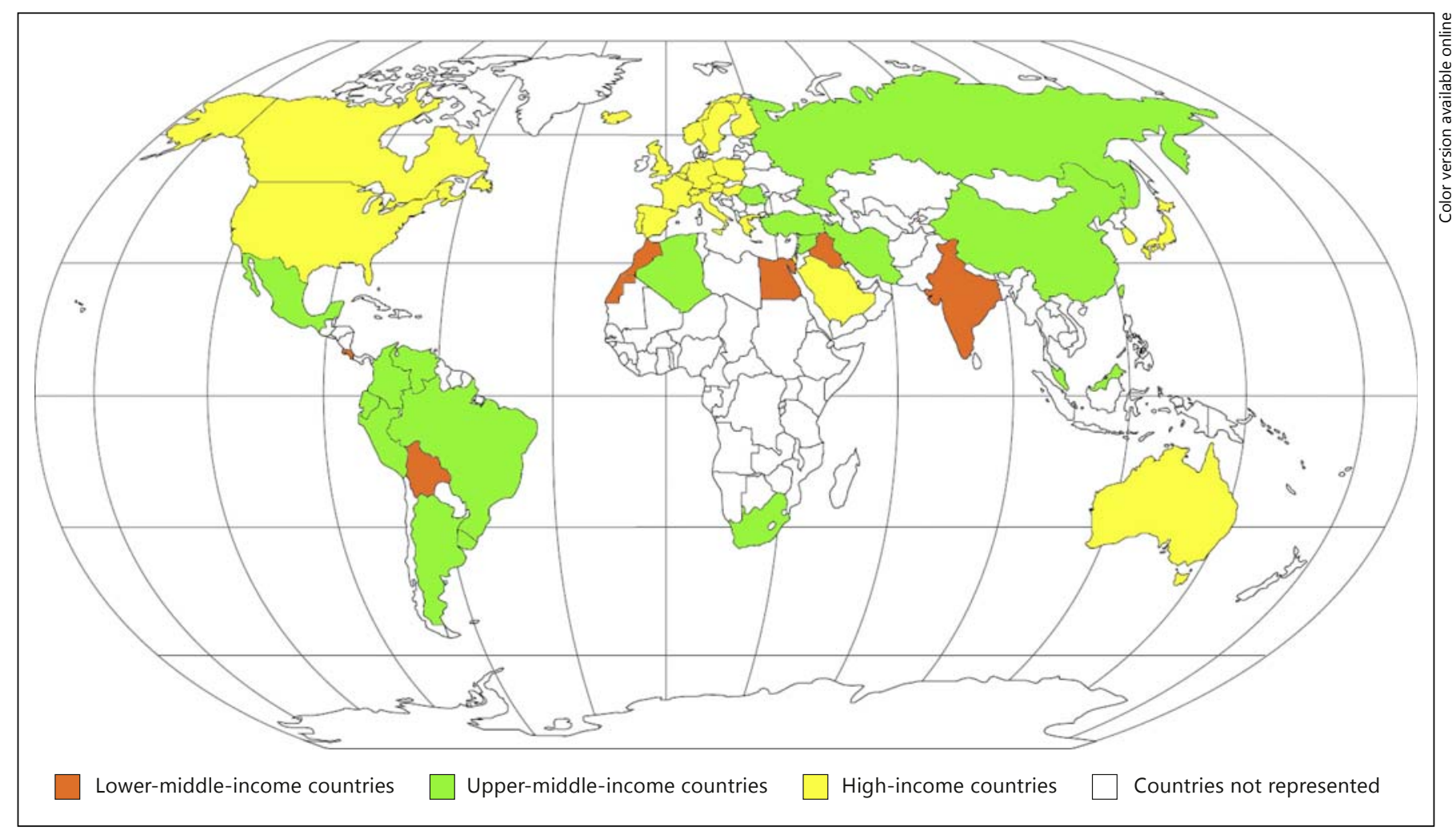

Fig. 1. Countries represented by respondents to the survey, classified by the country's economic development according to the World Bank classification.

in this field are published by a limited number of leading centers in developed countries. In fact, the experience in emerging countries is practically unknown. Therefore, the global use of neurosurgical treatments for PD considering health economics, health care professionals involved in PD teams, preferred surgical procedures and morbidity/mortality is yet to be studied. As a result, the current knowledge and experiences related to stereotactic surgery for movement disorders are biased. The aim of this study was to investigate the clinical practice of neurosurgical treatments for PD with emphasis on the grade of economic development of countries around the world.

\section{Methods}

The World Society for Stereotactic and Functional Neurosurgery (WSSFN) approved the study design. Its Board of Directors had access to the raw data all the time during the study. To capture a global perspective, a survey was sent worldwide focusing exclusively on neurosurgeons who perform stereotactic neurosurgery to treat movement disorders. A link to an Internet-based survey administered by iSalient (www.activecampaign.com) was e-mailed to participants. The survey consisted of specific questions on movement disorder surgery performed in 2009. The questionnaire was made available in English. Lists of names and e-mail addresses were provided by the WSSFN, the European Society for Stereotactic and Functional Neurosurgery (ESSFN), the American Society for Stereotactic and Functional Neurosurgery (ASSFN), the Latin American Society for Stereotactic and Functional Neurosurgery (SLANFE) and the Australian and Asian Society for Stereotactic and Functional Neurosurgery (AASSFN). In addition, names and e-mail addresses were found in neurosurgical journals and PubMed using results from the last 10 years for the following key words: DBS, thalamotomy, pallidotomy, and subthalamotomy. E-mail invitations were sent to all potential participants $(\mathrm{n}=$ $1,098)$. Some declined to participate in the survey $(n=21)$ because they were retired, no neurosurgeons, or not involved in movement disorder surgery.

The results obtained were provided exclusively by neurosurgeons working on movement disorders ( $\mathrm{n}=404,37 \%$ response). Data from incomplete questionnaires were discarded $(\mathrm{n}=51)$. Thus, the results of this present study are from 353 respondents. Two hundred and forty-nine participants (70.5\%) were from countries with high incomes, 91 (27.8\%) from upper-middle-income countries, and 13 (3.7\%) from lower-middle-income countries, according to The World Bank [3] in 2011 (fig. 1). The World Bank classification is based on the gross national income of each country. Fifty-one countries were represented in the study: 111 
Table 1. Characteristics of respondents included in this study

\begin{tabular}{lc}
\hline Characteristics & $\mathrm{n}(\%)$ \\
\hline Level of training & \\
$\quad$ Board-certified neurosurgeons & $327(92.6)$ \\
$\quad$ Residents in neurosurgery & $26(7.4)$ \\
Continent of country & \\
North America & $111(31.4)$ \\
Europe & $110(31.2)$ \\
Asia & $77(21.8)$ \\
Central-South America & $37(10.5)$ \\
Middle East & $9(2.5)$ \\
Oceania & $6(1.7)$ \\
Africa & $3(0.8)$ \\
Classification by country (by income) & \\
High income & $249(70.5)$ \\
Upper-middle income & $91(27.8)$ \\
Lower-middle income & $13(3.7)$ \\
Number of patients operated in 2009 & \\
High-income countries & $8,791(66.6)$ \\
Upper-middle-income countries & $4,223(32.0)$ \\
Lower-middle-income countries & $186(1.4)$ \\
Ratio of number of procedures/number of patients in 2009 \\
1-1.2 & $249(72.0)$ \\
More than 1.2 & $82(23.7)$ \\
No surgeries in 2009 & $17(4.3)$ \\
\hline
\end{tabular}

respondents (31.4\%) were from North America, 110 (31.2\%) from Europe, 77 (21.8\%) from Asia, 37 (10.5\%) from Central and South America, 9 (2.5\%) from the Middle East, 6 (1.7\%) from Oceania, and $3(0.8 \%)$ from Africa.

To identify the degree of development and the global distribution of publications about surgery for movement disorders, a systematic search was undertaken in papers published in scientific journals in the last 10 years using the term 'Parkinson's disease' along with the terms 'pallidotomy', 'thalamotomy', 'subthalamotomy' and 'deep brain stimulation'. All the retrieved references were classified according to the country of origin and its degree of economic development according to the World Bank.

Data Analysis

The Student $t$ test was used to compare two data sets. All other data were analyzed using the $\chi^{2}$ test. In the figures, all values are presented as a percentage. A p value $<0.05$ was considered significant. Analyses were conducted using SAS software, version 9.2.

\section{Results}

Responses from 353 neurosurgeons were included in this survey. Together they had operated on 13,200 patients with movement disorders in 2009. The demographic data are presented in table 1.

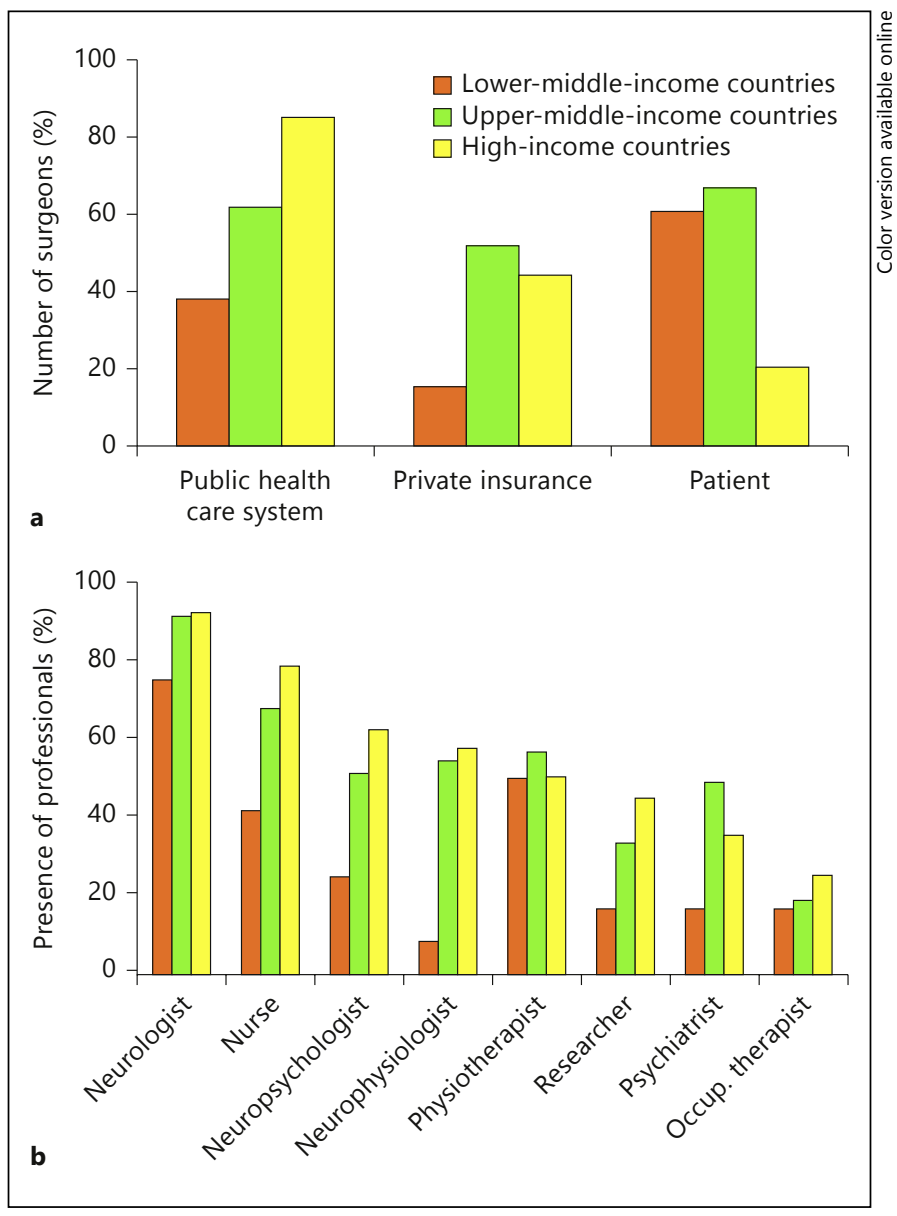

Fig. 2. a Economic support. The public health care system was the main source of financing in high-income countries, whereas the patients paid more often their surgeries in lower-middle-income and upper-middle-income countries. b The presence of professionals working with the neurosurgeon considering the country's economic development according to the World Bank classification. Lower-middle-income countries had less professionals working with the neurosurgeons compared to upper-middle-income and high-income countries $(\mathrm{p}<0.001)$.

\section{Economic Aspects}

Four different sources of financial support for surgical treatment were included in the survey: public health care systems, private insurance, self-financing by patients, and nonprofit foundations. Nearly half of the surgeons (47.2\%) reported having more than one source of financing. Taking all respondent information together, the public health care system was shown to be the most common source of financing (80.1\% of respondents), followed by self-financing patients $(46.8 \%)$, and private insurance (38.3\%). Significant differences between the sources of funding were observed when divided into the countries' development (fig. 2a). Sur- 


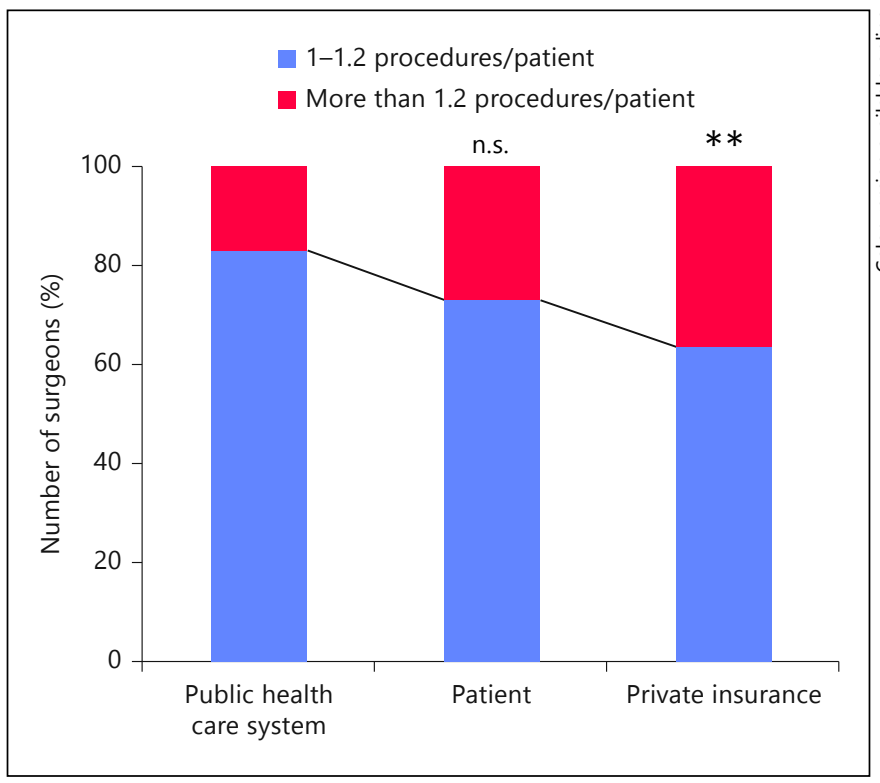

Fig. 3. Ratio number of procedures versus number of patients per year. A lower ratio (below) was observed when surgical procedures were financed by a public health care system compared to the patient (n.s.) or by the private insurances. ${ }^{* *} \mathrm{p}<0.01$.

geries in high-income countries were more frequently financed by the public health care system $(87 \%)$, whereas this source was present in 39 and $63 \%$ of the lower-middle-income and upper-middle-income countries, respectively ( $\mathrm{p}$ $<0.0001)$. Conversely, patients financed their own surgical treatment in 62 and $68 \%$ of the lower-middle-income and upper-middle-income countries, respectively, whereas only $21 \%$ of patients paid for their treatments in high-income countries $(\mathrm{p}<0.0001)$. Private insurance was the least reported source of financing and tended to be less common in lower-middle-income and upper-middle-income countries $(p=0.07)$. Finally, nonprofit foundations rarely funded any of the surgeries (less than $3 \%$ ), regardless of the country's income.

Regarding PD surgical treatment, better results are usually obtained using bilateral DBS, which can be performed in either one- or two-stage procedures. A ratio for each respondent was calculated based on the number of procedures done in 2009 divided by the number of patients operated on. A ratio of 1 indicates that each patient was operated on once, whereas a ratio of 2 indicates that each patient was operated on twice. For the analysis, the respondents with a ratio between 1 and 1.2 were regrouped together considering that some patients might need to be operated on again (median $=1$, mean $=1.01$ ). The respondents with a ratio over 1.2 up to 2 were pooled in a second group (median $=1.6$, mean $=1.66)$. The distribution between these two groups varied according to the source of financing (fig. 3). When surgeries were paid by private insurance, $36.8 \%$ of the neurosurgeons performed two-stage surgeries (ratio over 1.2-2). Interestingly, this percentage decreases to $17 \%$ in a public health care system $(\mathrm{p}<0.01)$, showing that patients operated within a public health care system were more likely to be operated on in a one-stage procedure compared to other sources of financing. Stereotactic surgery for movement disorders requires an interdisciplinary approach in order to select patients appropriately and to follow them adequately after surgery. The team compositions, divided according to the source of financing and the countries' income, are shown in figure $2 \mathrm{~b}$. Teams financed by public health care systems were larger $(4.8 \pm$ 0.1 members per team) than those financed by nonpublic health care systems $(4.1 \pm 0.2 ; \mathrm{p}=0.003)$. There were no major differences in the percentages of professionals present among the upper-middle-income and high-income countries. In contrast, lower-middle-income countries tended to have fewer professionals working with the neurosurgeons $(3.5 \pm 1.1)$. As expected, neurologists and nurses were the most common team members, whereas occupational therapists were less frequently included. The presence of researchers is higher in higher-income countries, reported as being up to $40 \%$ in these countries. Neurophysiologists are present in half of the high-income and upper-middle-income countries, whereas they are almost absent in lower-middle-income countries. Few neurosurgeons reported working alone $(1.2 \%)$.

\section{Development of PD Surgery Worldwide}

We identified 342 publications on the surgical treatment for PD in PubMed for 2009. The vast majority of the studies were derived from high-income countries (89.5\%), whereas fewer publications originated from upper-middle-income countries $(9.9 \%)$ or lower-middle-income countries $(0.6 \%)$. These ratios remained similar over the 10 -year period preceding 2009 (data not shown). When the modality of the treatment is considered, publications on ablative surgeries (thalamotomy, pallidotomy and subthalamotomy) accounted for only $7 \%$ of the total number of publications on PD in 2009, equally distributed between upper-middle-income and high-income countries $(\mathrm{n}=12$ each). The publications on ablative surgeries represented $35 \%$ of all publications in upper-middle-income countries and a mere $3.9 \%$ in high-income countries. Thus, there is a predominance of publications DOI: $10.1159 / 000355215$
Jourdain/Schechtmann 


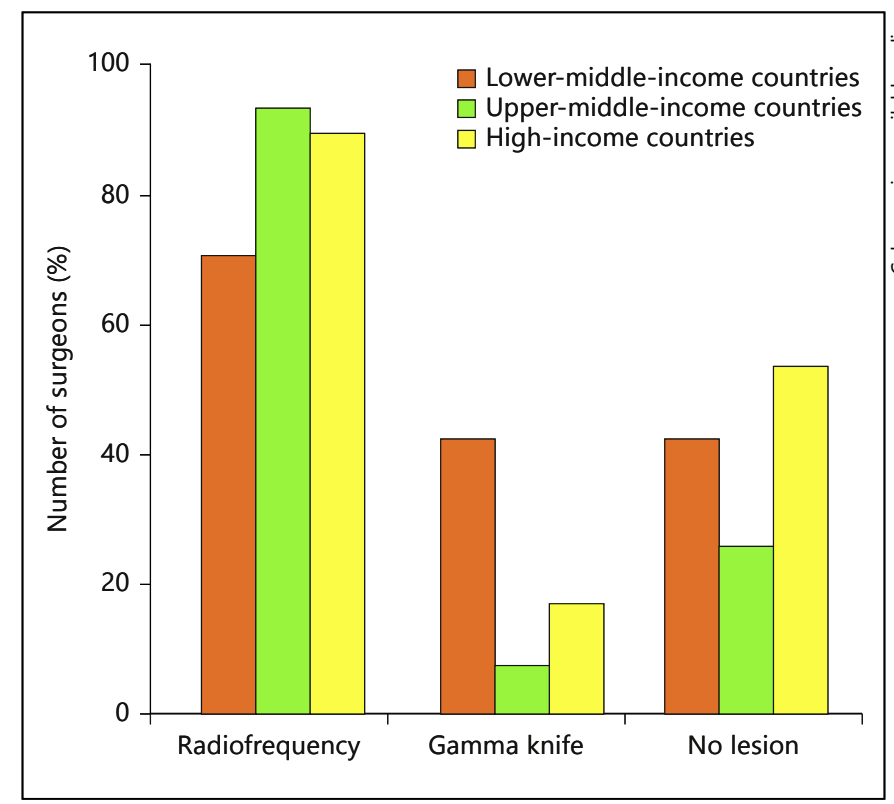

Fig. 4. Methods of lesioning. Radiofrequency lesion was the most common method of lesioning worldwide. Gamma knife was more used in lower-middle-income countries $(\mathrm{p}<0.05)$ compared to upper-middle-income and high-income countries. Ablative surgeries are more often practiced in lower-middle-income and highincome countries than in upper-middle-income countries $(\mathrm{p}<$ $0.001)$.

on DBS in high-income countries (96\%) compared to upper-middle-income countries (65\%). Surprisingly, in our survey population, $63.4 \%$ of respondents were still using ablative methods, whereas the remaining $36.6 \%$ reported not applying ablative surgeries (of these $36.6 \%, 43,26$ and $54 \%$ belong to the lower-middle-income, upper-middleincome, and high-income countries, respectively). Of those still applying ablative surgeries, $15.5 \%$ reported using more than one ablative technique. Radiofrequency is still the most widely used method for lesioning (90.6\%, $\mathrm{p}<0.001)$, followed by gamma knife use $(19.2 \%)$. The distribution of the ablative surgery method according to the countries' income is shown in figure 4 .

\section{Surgical Aspects}

Respondents were asked to identify the surgical target they used for lesions and DBS, respectively, when treating $\mathrm{PD}$, and whether it was used in all cases, in most cases, or only in selected cases. They were also asked if the lesions were unilateral or bilateral. The results are presented in figure $5 \mathrm{a}-\mathrm{c}$. Interestingly, both unilateral pallidotomy and thalamotomy were the most used targets for selected cases (approx. 70\%). Bilateral lesions were less frequent

Stereotactic Surgery for Parkinson's

Disease
$(<30 \%)$. In contrast, the STN was by far the preferred target for DBS for most cases (68.3\%) and for all cases $(20.3 \%)$. The ventrointermedian thalamic nucleus (49.5\%) and the GPi (52\%) were those mainly chosen in selected cases. The vast majority of surgeons (86.9\%) perform bilateral DBS implantations.

Respondents were asked to indicate the kind of complications that occurred and how often they were observed. The complications were divided into two categories: surgical and DBS hardware-related complications (table 2). Confusion (3.4\%) and dysarthria/dysphonia (3.4\%) were the most frequently reported surgical complications, followed by cognitive and psychiatric disturbances (2.5 and $1.5 \%$, respectively). Major complications, including intracerebral hemorrhages (1.3\%), visual field deficits $(0.2 \%)$ and death $(0.1 \%)$, were rare. Intracerebral hemorrhage was significantly related to the use of microelectrode recording ( $\mathrm{p}<0.0001)$, whether single-track or multi-track microelectrode recording was performed. Infections were the most frequent hardware-related complications $(3.2 \%)$. The number of explantations performed increased proportionally with the number of patients operated on per year $(\mathrm{p}<0.0001)$, but remained infrequent $(2.8 \%)$.

\section{Discussion}

This global survey on neurosurgical treatments for PD relies on the largest clinical database, and included 13,200 patients and over 350 neurosurgeons involved in surgery for movement disorders. The large number of respondents from all continents provides a new and unprecedented picture of the health economics, sociodemographic and surgical aspects of PD. Particular attention was given to otherwise unreported, rare but major complications illustrating the actual risk of neurosurgical treatments for movement disorders. Few surveys were published in the last two decades, and those that were are restricted to only specific subgroups of neurosurgeons mainly from North America or to a handful of experts from Europe [4-7].

\section{Economic Aspects}

The requirements to perform stereotactic neurosurgery are very high in terms of medical training, adequate environment, and technology. Less expensive techniques such as ablative methods, still used in higherincome countries, may be a reasonable strategy for emerging countries to overcome barriers in the treat- 
Fig. 5. Targets for PD as preferred by the 353 neurosurgeons participating in the study. a Unilateral and b bilateral lesions. c DBS. CM/Pf = Centromedian/parafascicular thalamic nuclei; PPN = pedunculopontine nucleus; VIM = ventrointermedian thalamic nucleus.

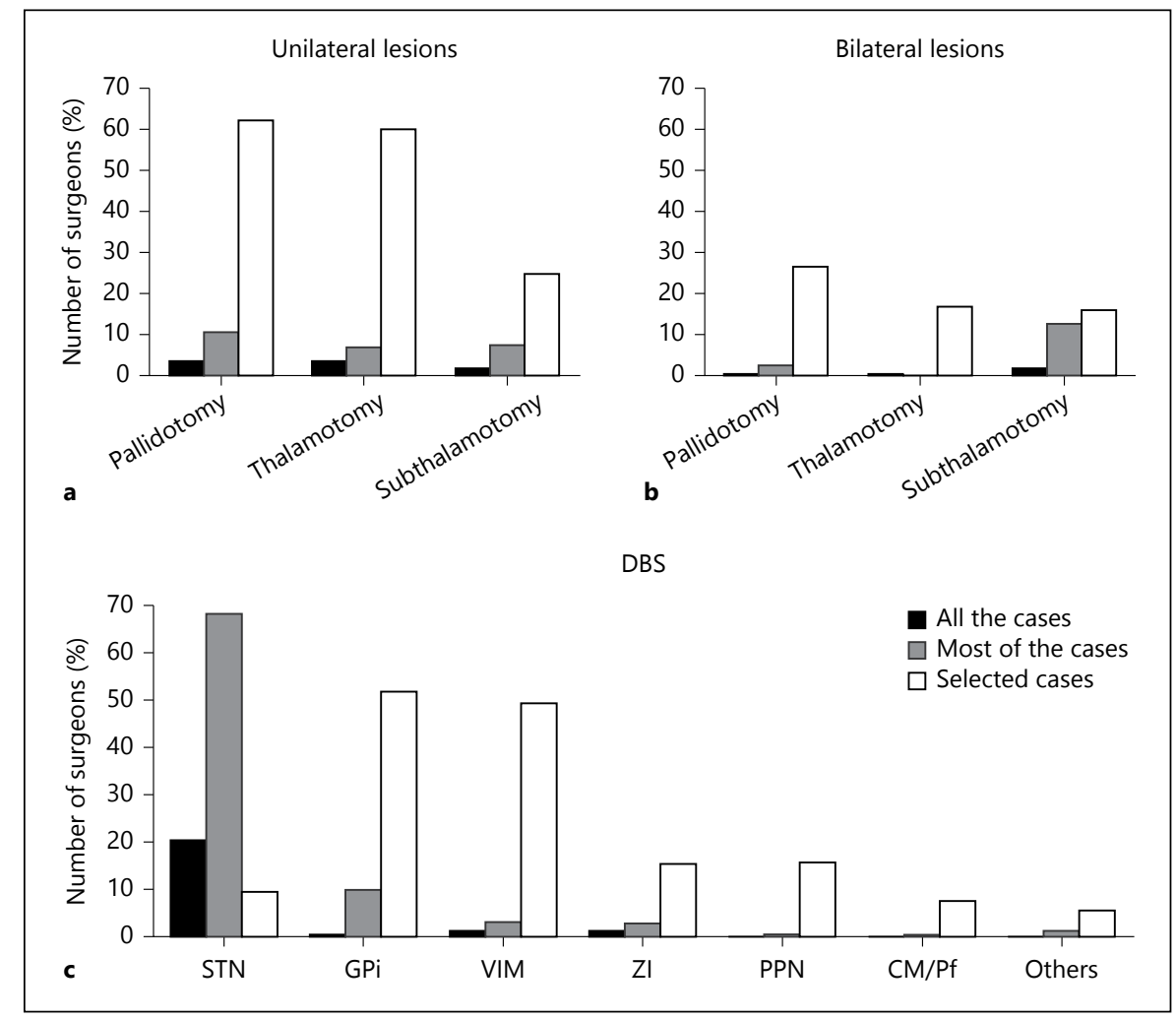

Table 2. Surgical and hardware-related complications

\begin{tabular}{ll}
\hline & Frequency, \% \\
\hline Surgical complications & \\
Blepharospasm & 0.4 \\
Cognitive disturbance & 2.5 \\
Confusion & 3.4 \\
Dysarthria/dysphonia & 3.4 \\
Intracerebral hemorrhage & 1.3 \\
Paresis/gait disturbance & 1.0 \\
Psychiatric disturbance & 1.5 \\
Seizures & 0.7 \\
Visual field deficits & 0.2 \\
Death & 0.1 \\
Hardware-related complications & \\
Infections & 3.2 \\
Electrode migration & 1.0 \\
Lead fracture & 1.2 \\
\hline
\end{tabular}

ment of PD patients. Today, these approaches are unfortunately far from being prioritized in low-income and most of the lower-middle-income countries. The role of national health care programs for PD patients that receive neurosurgical treatment has been a success- ful one in high-income countries. The awareness of decision makers in these countries that movement disorder surgery needs to rely on public health care systems reinforces this policy [8]. Fewer procedures per patient were observed when patients were operated on under a public health care system, compared to the number of procedures financed by private insurance, or those that the patients paid for themselves. This could be explained by the fact that public health care systems need to be more efficient in terms of lowering per-patient costs, especially when one considers the significantly increased cost of staged bilateral surgery compared to simultaneous DBS surgeries [9].

\section{Multidisciplinary Teams in PD Surgery}

Due to the natural progression of this neurodegenerative disease, PD patients become progressively incapacitated by motor and nonmotor symptoms [10]. Therefore, a multidisciplinary team approach plays an important role in the management and outcome of PD treatments. We observed that the composition of multidisciplinary teams, as well as the number of health care professionals on the teams, varies widely between countries, including between countries of the same income level. However, the 
lack of financial support available to build a multidisciplinary PD team is a clear obstacle in lower-middle-income countries. Also, the number of team members tends to increase when patients are operated on under a public health care system versus surgeries that are financed by private insurance or paid for by the patients.

\section{Surgical Targets}

In the current literature, there is no consensus on which anatomical target is preferable for the treatment of PD [2]. There is growing interest in double-blind studies that compare bilateral stimulation of the GPi versus the STN [11]. Thus, we explored which structures were targeted for both lesions and DBS. Unexpectedly, ablative techniques were still used by two thirds of the respondents. Unilateral lesions were usually performed in selected cases and few bilateral lesions were reported. This may be explained by the fact that some bilateral lesions increase the risks of speech and cognitive disturbances $[12,13]$. Notwithstanding the fact that these procedures are irreversible, ablative surgeries remain an alternative to DBS for patients for whom stimulation is contraindicated or unavailable for economic/access to care reasons [14]. Concerning DBS targets for the treatment of PD, over $85 \%$ of the surgeons targeted the STN at least in most of their cases, which closely resembles results obtained in a similar survey [15]. Other targets were used mainly in selected cases, probably where patients displayed more specific cardinal symptoms (i.e. ventrointermedian thalamic nucleus for parkinsonian tremor), other symptoms (i.e. pedunculopontine nucleus for freezing of gait) or contraindications for STN (i.e. depression) [16]. Surprisingly, the pedunculopontine nucleus was reported to be a target as often as the zona incerta was, despite the fact that the pedunculopontine nucleus is a relatively new target that is not yet well established [17], whereas the zona incerta has been used for decades in stereotactic surgery.

The surgical practices reported in this study clearly contrast what had been published in the literature. Regarding ablative surgeries, 35 and $4 \%$ of the articles on this subject were published in upper-middle-income and high-income countries, respectively, whereas nearly 75\% (from upper-middle-income countries) and 50\% (from high-income countries) of surgeons were still performing ablative surgeries in 2009. Reasons for these discrepancies remain to be addressed, but trying to avoid redundancy and the limited number of cases per year may be some of the explanations. Another explanation is that lesional surgery is not 'mainstream' anymore, and perhaps

Stereotactic Surgery for Parkinson's

Disease some editors and reviewers are reluctant to accept papers detailing 'obsolete' procedures such as thalamotomy and pallidotomy versus the more exciting DBS. Another important difference relies on the fact that nearly $90 \%$ of the publications were derived from high-income countries, accounting for $67 \%$ of the total number of patients. The remaining $32 \%$ of the patients were operated on in upper-middle-income countries, from which merely $10 \%$ of the publications originated. The limited presence of researchers could explain the lower percentage of publications from lower-middle-income and upper-middleincome countries. All complications reported in this survey remained infrequent (less than $4 \%$ ), and were lower when compared to the results previously reviewed [1820].

A careful selection of patients is one of the best ways to achieve the best outcomes while keeping the number of adverse events (mainly cognitive and neuropsychological side effects) as low as possible. Once again, this shows the importance of a multidisciplinary approach for the treatment of PD [21]. The most common type of major complication was intracerebral hemorrhage. This particular complication leads to increased disabilities and higher rates of death [22]. In the present study, $1.3 \%$ of the 13,200 patients presented an intracerebral hemorrhage after surgery. This percentage is consistent with the current consensus between neurosurgical experts [23]. It has recently been reviewed that the use of microelectrode recording may increase the risk of intracerebral hemorrhage [24]. In this line of thought, we observed similar results that both single- and multi-track recordings were highly correlated to an increased risk of this complication.

\section{Study Limits}

Despite gathering information from a very large number of participants across more than 50 countries, this study has some limitations. Names and contact information were provided by societies for stereotactic and functional neurosurgery or found through publications. Thus, surgeons that are not society members or that do not publish articles may have been missed in the recruitment process. The true number of noninclusive participants remains unknown since some of those contacted could have been retired, they might not have been neurosurgeons, or they might not have been involved in movement disorders. Further, since data was originated by neurosurgeons and not by centers, some redundancy might have occurred, despite the fact that some participants may practice in more than one center in the same city. Secondly, 
the academic purpose of the study was explained to the surgeons, and they were invited to participate on a voluntary basis. There were no incentives to participate in the study. Lastly, participants were asked to fill out the survey according to their practice in 2009. Although all questions were carefully written to avoid confusion and the need to check in their archives, some involuntary omissions/additions in the questions regarding numbers (patients, procedures, explantations, and complications) may have occurred.

\section{Conclusion}

This study identifies the worldwide economic barriers of the surgical treatment for $\mathrm{PD}$, showing that public health care systems are the main source of funding in high-income countries, whereas patients mostly finance their own surgeries in lower-middle-income and uppermiddle-income countries. Moreover, it appears that more procedures are performed per patient when financed by private insurance compared to those financed by the patients and by public health care systems. The composition of PD treatment teams also varies depending on a country's income, with larger teams formed in upper-middleincome and high-income countries. Decision makers in high-income countries have been aware of the medical needs of these patients and rely on a public health care system to reinforce this policy. The present study provides evidence that ablative surgeries are still very much practiced and are reserved mostly for selected cases, whereas DBS of the STN is by far the most commonly used target for the treatment of PD. The number of surgical complications is low and this may be a result of appropriate patient selection and extensive technical development over the last two decades. Finally, global educational and training programs that aim to finance efforts to scale up PD surgical treatments financed by public health care systems are warranted.

\section{Acknowledgements}

The authors would like to thank the Board of Directors of the WSSFN for the approval of the project, in particular Prof. Takaomi Taira and Prof. Joachim Krauss for their positive critical comments and generous support during the initial phase of this study, Assoc. Prof. Per Almqvist and Dr. Ludvic Zrinzo for their critical input, as well as the boards of the ASSFN, ESSFN, SLANFE, and AASSFN for providing a list of their members. The authors would like to thank all the colleagues that participated in the study and the Swedish Parkinson's Foundation (Parkinson Förbundet). This study was supported by a grant from the Swedish Parkinson's Disease Foundation (ParkinsonFonden).

\section{References}

1 Guridi J, Obeso JA, Rodriguez-Oroz MC, Lozano AA, Manrique M: L-dopa-induced dyskinesia and stereotactic surgery for Parkinson's disease. Neurosurgery 2008;62:311323.

2 Follett KA, Weaver FM, Stern M, Hur K, Harris CL, Luo P, Marks WJ, Rothlind J, Sagher O, Moy C, Pahwa R, Burchiel K, Hogarth P, Lai EC, Duda JE, Holloway K, Samii A, Horn S, Bronstein JM, Stoner G, Starr PA, Simpson R, Baltuch G, de Salles A, Huang GD, Reda DJ, Group CS: Pallidal versus subthalamic deepbrain stimulation for Parkinson's disease. N Engl J Med 2010;362:2077-2091.

3 The World Bank Bank: http://data.worldbank. org/about/country-classifications/countryand-lending-groups (accessed December 8, 2011).

4 Gildenberg PL, Franklin PO: An informal survey of stereotactic and functional neurosurgery. Stereotact Funct Neurosurg 1994;63: 104-123.

5 Ondo WG, Bronte-Stewart H, Group DS: The North American survey of placement and adjustment strategies for deep brain stimulation. Stereotact Funct Neurosurg 2005;83:142-147.
6 Favre J, Taha JM, Nguyen TT, Gildenberg PL, Burchiel KJ: Pallidotomy: a survey of current practice in North America. Neurosurgery 1996;39:883-890, discussion 890-892.

7 Laitinen LV: Brain targets in surgery for Parkinson's disease. Results of a survey of neurosurgeons. J Neurosurg 1985;62:349-351.

8 Spottke EA, Volkmann J, Lorenz D, Krack P, Smala AM, Sturm V, Gerstner A, Berger K, Hellwig D, Deuschl G, Freund HJ, Oertel WH, Dodel RC: Evaluation of healthcare utilization and health status of patients with Parkinson's disease treated with deep brain stimulation of the subthalamic nucleus. J Neurol 2002;249:759-766.

-9 McClelland S III: A cost analysis of intraoperative microelectrode recording during subthalamic stimulation for Parkinson's disease. Mov Disord 2011;26:1422-1427.

10 Toulouse A, Sullivan AM: Progress in Parkinson's disease - Where do we stand? Prog Neurobiol 2008;85:376-392.

11 Moro E, Lozano AM, Pollak P, Agid Y, Rehncrona S, Volkmann J, Kulisevsky J, Obeso JA, Albanese A, Hariz MI, Quinn NP, Speelman JD, Benabid AL, Fraix V, Mendes
A, Welter M-L, Houeto J-L, Cornu P, Dormont D, Tornqvist AL, Ekberg R, Schnitzler A, Timmermann L, Wojtecki L, Gironell A, Rodriguez-Oroz MC, Guridi J, Bentivoglio AR, Contarino MF, Romito L, Scerrati M, Janssens M, Lang AE: Long-term results of a multicenter study on subthalamic and pallidal stimulation in Parkinson's disease. Mov Disord 2010;25:578-586.

12 Ghika J, Ghika-Schmid F, Fankhauser H, Assal G, Vingerhoets F, Albanese A, Bogousslavsky J, Favre J: Bilateral contemporaneous posteroventral pallidotomy for the treatment of Parkinson's disease: neuropsychological and neurological side effects. Report of four cases and review of the literature. J Neurosurg 1999;91:313-321.

$\checkmark 13$ de Bie RM, Schuurman PR, Esselink RAJ, Bosch DA, Speelman JD: Bilateral pallidotomy in Parkinson's disease: a retrospective study. Mov Disord 2002;17:533-538.

14 Hooper AK, Okun MS, Foote KD, Fernandez HH, Jacobson C, Zeilman P, Romrell J, Rodriguez RL: Clinical cases where lesion therapy was chosen over deep brain stimulation. Stereotact Funct Neurosurg 2008;86:147-152. 
15 Abosch A, Timmermann L, Bartley S, Rietkerk HG, Whiting D, Connolly PJ, Lanctin D, Hariz MI: An international survey of deep brain stimulation procedural steps. Stereotact Funct Neurosurg 2012;91:1-11.

16 Ponce FA, Lozano AM: Deep brain stimulation state of the art and novel stimulation targets. Prog Brain Res 2010;184:311-324.

-17 Pahapill PA, Lozano AM: The pedunculopontine nucleus and Parkinson's disease. Brain 2000;123:1767-1783.

18 Hamani C, Lozano AM: Hardware-related complications of deep brain stimulation: a review of the published literature. Stereotact Funct Neurosurg 2006;84:248-251.
19 Baizabal Carvallo JF, Simpson R, Jankovic J: Diagnosis and treatment of complications related to deep brain stimulation hardware. Mov Disord 2011;26:1398-1406.

20 Videnovic A, Metman LV: Deep brain stimulation for Parkinson's disease: prevalence of adverse events and need for standardized reporting. Mov Disord 2008;23:343-349.

21 Houeto JL, Damier P, Bejjani PB, Staedler C, Bonnet AM, Arnulf I, Pidoux B, Dormont D, Cornu P, Agid Y: Subthalamic stimulation in Parkinson disease: a multidisciplinary approach. Arch Neurol 2000;57:461-465.

22 Qureshi AI, Mendelow AD, Hanley DF: Intracerebral haemorrhage. Lancet 2009;373: 1632-1644.
23 Bronstein JM, Tagliati M, Alterman RL, Lozano AM, Volkmann J, Stefani A, Horak FB, Okun MS, Foote KD, Krack P, Pahwa R, Henderson JM, Hariz MI, Bakay RA, Rezai A, Marks WJ, Moro E, Vitek JL, Weaver FM, Gross RE, DeLong MR: Deep brain stimulation for Parkinson disease: an expert consensus and review of key issues. Arch Neurol 2011;68:165-171.

24 Zrinzo L, Foltynie T, Limousin P, Hariz M: Reducing hemorrhagic complications in functional neurosurgery: a large case series and systematic literature review. J Neurosurg 2012;116:84-94. 